\title{
MARCAS DA PASSAGEM DO TEMPO: UM RELATO DE EXPERIÊNCIA GERONTO EDUCACIONAL NA UNIVERSIDADE DA TERCEIRA IDADE NO SUL DO BRASIL.
}

\author{
SIGNALS OF THE PASSAGE OF TIME: A REPORT OF A GERONTO EDUCATIONAL \\ EXPERIENCE AT THE UNIVERSITY OF THE OLD AGE IN SOUTH OF BRAZIL.
}

\begin{abstract}
MARCAS DEL PASO DEL TIEMPO: UN RELATO DE EXPERIENCIA GERONTO EDUCACIONAL EN LA UNIVERSIDAD DE LA TERCERA EDAD EN EL SUR DEL BRASIL.
\end{abstract}

Maria Cecília Antônia Godtsfriedt

\begin{abstract}
Resumo: Uma das maiores conquistas culturais de um povo em seu processo de humanização é o envelhecimento de sua população, refletindo uma melhoria das condições de vida. De acordo com projeções das Nações Unidas (Fundo de Populações) "uma em cada 9 pessoas no mundo tem 60 anos ou mais, e estima-se um crescimento para 1 em cada 5 por volta de 2050”. Com esse cenário humano, o envelhecimento da população idosa desafia os espaços sócios educacionais nas Instituições Brasileiras de Ensino Superior- IES. O Núcleo de Estudos da Terceira Idade- NETI, da UFSC, desenvolve um projeto de extensão, Curso de Formação de Monitores da Ação Gerontológica- CFMAG, que há de duas décadas, no propósito de qualificar pessoas idosas em gerontologia, vem proporcionando novos conhecimentos, estimulando ao voluntariado junto a projetos sociais, e de modo especial, como esse idoso, esta se preparando para a sua velhice. O CFMAG tem sua grade curricular, pautada pela teoria pedagógica dos Quatro Pilares da Educação, (Delors, 2000). Foi oportunizado, ao grupo de alunos uma reflexão sobre a perspectiva da passagem do tempo das suas vidas e como esse Tempo, refletir e dar significados junto as suas relações sociais e familiares. Assim na perspectiva dos Destinos traçados pelas influências míticas dos Deuses gregos Chronos e Kairós, os alunos foram levados a pensar sobre o curso de suas vidas frente ao envelhecimento. O pensar em envelhecer e o investimento na rotina de suas vidas foram pontos de discussões da experiência aqui relatada.
\end{abstract}

Palavras Chave: Envelhecimento. Passagem do Tempo. Socialização.

\begin{abstract}
One of the greatest cultural achievements of a people in process of humanization is the aging of its population, reflecting an improvement in the living conditions. According to projections by the United Nations (Population Fund), "one out of every 9 people in the world is 60 or older, and growth is estimated to be 1 in 5 by 2050.” With this human scenario, the aging of the elderly population challenges the educational partner spaces in Brazilian Institutions of Higher Education (IES). The Center for the Study of the Old Age - NETI, UFSC, develops an extension project, Training Course of Monitors of Gerontological Action - CFMAG, which for two decades, in order to qualify elderly people in gerontology, has been providing new knowledge, stimulating volunteering along with social projects, and especially how this elderly is preparing for their old age. The CFMAG has its curriculum guided by the pedagogical theory of the Four Pillars of Education (Delors, 2000). The group of students was given a reflection on the perspective of the passage of time in their lives and how this Time reflects and has
\end{abstract}

\footnotetext{
*Assistente Social, Especialista em gerontologia na Universidade Federal de Santa Catarina/Pró-Reitoria de Extensão/ Núcleo de Estudos da Terceira Idade. Email:maceago58@gmail.com
} 
meanings together with their social and family relations. Thus from the perspective of the Fates drawn by the mythical influences of the Greek Gods, Chronos and Kairos, students were led to think about the course of their lives in the face of aging. The thought of aging and investing in the routine of their lives were points of discussion of the experience reported here.

Keywords: Aging. Passage of time. Socialization.

Resumen: Una de las mayores conquistas culturales de un pueblo, en su proceso de humanización, es el envejecimiento de su población, que refleja una mejoría de las condiciones de vida. De acuerdo con proyecciones de las Naciones Unidas (Fondo de Poblaciones) "una de cada 9 personas, en el mundo, tiene 60 años o más y se estima un crecimiento para 1 de cada 5 personas para el 2050”. Con ese escenario humano, el envejecimiento de la población adulta mayor desafía los espacios socio-educacionales en las Instituciones Brasileñas de Enseñanza Superior- IES. El Núcleo de Estudios de la Tercera Edad NETI, de la UFSC, desarrolla un proyecto de extensión llamado Curso de Formación de Monitores de la Acción Gerontológica- CFMAG, desde hace dos décadas. El mismo tiene el propósito de calificar personas ancianas en gerontología, proporcionando nuevos conocimientos, estimulando el voluntariado junto a los proyectos sociales y, de forma especial, ese anciano se prepara para enfrentar su vejez. El CFMAG tiene su currículo pautado por la teoría pedagógica de los Cuatro Pilares de la Educación (Delors, 2000). Fue posible mostrar, para el grupo de alumnos, una reflexión sobre la perspectiva del paso del tiempo en sus vidas, y con ese Tiempo, reflexionar y dar significados junto a sus relaciones sociales y familiares. Así, en la perspectiva de los Destinos marcados por las influencias míticas de los Dioses Griegos Chronos y Kairós, los estudiantes fueron llevados a pensar sobre el curso de sus vidas frente al envejecimiento. Pensar en envejecer e invertir en la rutina de sus vidas fueron los puntos de discusión de la experiencia aquí relatada.

Palabras Clave: Envejecimiento. Paso del Tiempo. Socialización.

\section{Introdução}

Uma das maiores conquistas culturais de um povo em seu processo de humanização é o envelhecimento de sua população, refletindo uma melhoria das condições de vida. De acordo com projeções das Nações Unidas (Fundo de Populações), "uma em cada 9 pessoas no mundo tem 60 anos ou mais, e estima-se um crescimento para 1 em cada 5 por volta de 2050". Com esse cenário, o envelhecimento da população idosa desafia os espaços sócios educacionais nas Instituições Brasileiras de Ensino Superior- IES. As propostas trabalhadas no universo das IES estão fundamentadas por teorias pedagógicas e gerontológicas que oportunizam e despertam a pessoa idosa para a reflexão do seu contexto de vida, da sua condição biopsicossocial, principalmente quanto á importância de participação social inserindo-as nesses espaços públicos, na sociedade, com uma consciência cidadã de direitos e deveres.

Concordamos com Debert (1993) quando nos fala que os Idosos não são mais ausentes do conjunto de discursos produzidos, e que se fazem presentes nos debates, sobre políticas públicas, nas interpelações dos movimentos sociais e eleitorais e até mesmo na definição de ocupação de novos mercados de consumo e novas formas de educação e lazer. As novas tecnologias sócias educativas, como projetos e programas de extensão, levadas pelas IES, têm contribuído e legitimado uma nova gestão sobre o envelhecimento que vem a garantir a consagração política e mediática, frente ao impasse no âmbito social e familiar, dando divisas de responsabilidade social para todos os atores sociais. 
O Núcleo de Estudos da Terceira IdadeNETI, da UFSC, desenvolve um projeto de extensão, Curso de Formação de Monitores da Ação Gerontológica-CFMAG, que há vinte e cinco anos, no propósito de qualificar pessoas idosas em gerontologia, vem proporcionando novos conhecimentos e estimulando a prática do voluntariado junto a projetos sociais, e de modo especial, de como esse idoso tem o seu enfretamento com a sua velhice. O CFMAG vem propiciando a compreensão do processo de viver e envelhecer, potencializando a capacidade de ressignificação de convívio social e pessoal, na medida também que instrumentaliza e fortalece as ações transformadoras. O referido curso tem duração de quatro semestres, com encontros duas vezes por semana; carga horária de duzentos e cinquenta e seis horas, destinando-se preferencialmente para pessoas a partir dos 50 anos de idade. Os certificados são emitidos pela Pró- Reitoria de Extensão da Universidade Federal de Santa Catarina.

A organização curricular para o primeiro e segundo semestre compõem o bloco da Fundamentação Gerontológica I e II que reúne as disciplinas: Dinâmica I/II, Noções de Filosofia, de Gerontologia, de Psicologia de Antropologia; Para o terceiro semestre temos o bloco das Políticas e Programas da Ação Gerontológica- PPAG, reunindo as disciplinas, Noções de Sociologia, de Saúde, de Direito e Metodologia da Ação Gerontológica, e finalizando o quarto semestre temos o bloco da Pratica da Ação Gerontológica, constando das disciplinas Dinâmica III, Técnicas e Praticas da Ação Gerontológica e a Supervisão de Estágio. Para cada finalização dos semestres temos o desenvolvimento dos seminários reflexivos, no sentido de estar integrando os demais conhecimentos trabalhados num caráter extracurriculares, que acontecem numa média de duas a três sessões por ano, objetivando a compreensão do processo de ensino e aprendizagem.

O referencial dessa grade curricular aqui descrita ocupa-se com temas a serem desenvolvidos dentro das três grandes áreas sociais, humanas e saúde, sendo que o seu projeto pedagógico está fundamentado no referencial teórico dos Quatros Pilares da Educação (DELORS, 2000).

Dentro da disciplina Metodologia da Ação Gerontológica, na qual sou docente, apresentei a seguinte ementa à referida disciplina: Fundamentar os Procedimentos Metodológicos do Fazer Gerontológico na perspectiva de Educação Permanente, tendo como objetivo habilitar, promover e refletir acerca de situações do Fazer Gerontológico, propiciando estratégias de ensino-aprendizagem que venham a favorecer suas integrações entre o Conhecer, o Fazer, o Conviver e o Ser. Dentro da programação desenvolvida estava previsto um momento de manejo de trabalhos com Grupos Sociais e Idosos visando a integração entre o fazer gerontológico e o desenvolvimento de atividades e dinâmicas de acolhimento, de interação, de reflexão e de crescimento bio-psico-sócio-espiritual, na proposta de poder socializar as suas experiências vivenciadas.

Para que possa ocorrer uma ação pedagógica que venha suprir as motivações que trazem o aluno idoso a se lançar num programa de educação permanente junto as IES, é necessário que tenhamos conhecimento das características desse alunato, ou seja, seus propósitos de vida, que oportunizem a sua expressão, dando-lhes autonomia nas suas locuções e que se revelem agentes protagonistas do repertório históricos de suas vidas. Com igual importância também que os conteúdos propostos nos diversos programas atendam às expectativas sócias culturais dos públicos a serem atingidos. 
No desenvolvimento da disciplina os alunos retrataram depoimentos de quão são significativas às vivências em grupo, e que é possível aprenderem em grupo; cada um tem o seu caminho, às vezes vamos ter desencontros, sentem-se muito gratos de estarem vivendo essa experiência grupal que os leva a perceberem que podem contar com esse suporte social, levando-os, a uma tomada de consciência, de que, não é o Tempo que indica a forma de vivermos, mas das oportunidades que nos são proporcionadas.

Dentro do modelo, acredita-se que os aspectos de independência e autonomia, autodeterminação a construção subjetiva e social sobre o tempo real de suas vidas, foi oportunizado ao grupo de alunos uma reflexão sobre a perspectiva da passagem do tempo das suas vidas e como esse tempo ter significados junto as suas relações sociais e familiares. $\mathrm{O}$ pensar envelhecer e o investimento na rotina de suas vidas foram ponto de discussão entre os idosos engajados na turma do referido curso.

\section{Relato da experiência da atividade sócio- educativa desenvolvida com alunos idosos do CFMAG}

Assim, contextualizado e embasado pela proposta da disciplina do CFMAG, foi proposto para os alunos idosos, do CFMAG, uma atividade sócio-educativa "Marcas da passagem do Tempo: Destinos traçados pelos Deuses Chronos e Kairós”, objetivando que num plano individual dissertassem sobre o curso de suas vidas. Ou seja, refletissem sobre a passagem do Tempo; De como estão administrando esse Tempo? Se o Tempo passa? Ou Nós que passamos pelo Tempo?

Para facilitar o processo, solicitou-se que os alunos idosos pegassem uma folha de papel, na cor branca, (tipo Foscotex, tamanho A4 com $210 \mathrm{~mm}$ x $297 \mathrm{~mm}$ ) com espessura diferenciada das folhas de papel oficio. Foi solicitado que todos pudessem observar alguns aspectos: tipo, formato, cor, tamanho, leveza sobre a referida folha, e que projetassem para esse material a sua imagem corporal. Na sequência, pensassem em fatos ou acontecimentos que lhes aconteceram, numa perspectiva de um tempo passado. Foi sugerido um espaço de cinco anos atrás. Na continuidade, na medida em que essas lembranças favorecessem, deveriam fazer algumas marcas na referida folha (amassando a mesma) a cada instante que estivessem tendo essas lembranças remotas, para que fossem possíveis de serem recordadas.

No desenvolvimento do exercício, os alunos idosos foram lembrados, de que, quando refletimos essa dimensão de "um tempo passado", quase sempre podem vir em nossas mentes uma máxima comum levando-nos a questionar:

Será que estamos aproveitando, bem esse Tempo que nos foi oportunizado? Ou seja, a incógnita do Tempo nos faz refletir que, às vezes, o Tempo apresenta-se muito mais lento do que podemos vir a sentir, às vezes, mais intenso do que somos capazes de perceber e vários questionamentos afloraram.

Essa dualidade de Tempo e Destino sempre foi ponto de interrogação para todos nós. Os pensadores, inseridos num contexto histórico de sua época, buscaram diversos temas para reflexão. A Grécia Antiga é conhecida como o berço dos pensadores, sendo que os sophos (sábios em grego) buscaram formular, no século VI A.C, explicações racionais para tudo aquilo que era explicado, até então, através da mitologia.

Os antigos gregos viviam em uma civilização politeísta, ou seja, tinham a crença em vários deuses. Sempre quando os gregos tinham problemas sérios, eles consultavam os deuses por meio dos oráculos, que 
interpretavam para os seres humanos o que os deuses queriam.

Com o passar do tempo, nas cidades gregas, como Atenas, surgiram estudiosos que fundaram a Filosofia (os principais foram Sócrates, Platão e Aristóteles). Eles começaram a duvidar das explicações originárias da mitologia e fizeram-se valer do uso metódico da razão, elaborando outras explicações sobre os fenômenos naturais, sobre a vida e o homem. A partir de então, a mitologia passou a explicar, juntamente com a Filosofia, a origem da vida e os problemas da existência.

Entretanto, pensar nessa projeção de Tempo, de como o Tempo e o Destino, podem reger e guiar a ordem do Universo e de todos os seres vivos, tem sido de certa forma ainda, pontos de reflexão, não desse momento, mas se observarmos, desde os primórdios da história antiga, os gregos já tinham assim, duas palavras para designar a passagem do Tempo:

Chronos para o tempo que pode ser medido e Kairós para o tempo indeterminado. Como vimos a noção de Tempo influenciou os grandes pensadores, filósofos (Platão e Pitágoras) e toda humanidade, onde a história aponta-nos para essas figuras míticas, dos dois Deuses -Chronos como Deus de um tempo mensurável, linear, no qual todas as criaturas nascem, crescem, envelhecem e morrem. Na contrapartida da marcação do Tempo mensurável - CHRONOS, também nos foi apresentado pode-se também pensar na ideia de outro Deus do Tempo:

Kairós para o Deus do Tempo indeterminado, oportuno, da emoção o Tempo do momento certo. A compreensão dessa dualidade do tempo, expressa o “ mundo " que vivemos , essa noção de tempo sempre permeou às nossas Vidas; no nosso curso de vida podemos sentir as marcas dessa passagem. A história mítica nos traz que o corpo, que é a matéria, está submetido aos tempos de
Chronos, que quantifica e mantém a areia de nossa existência escorrendo pela Ampulheta imaginária. A alma, que é divina e eterna vive o tempo de Kairós, que nos traz um inicio, meio e fim. Por essa mesma razão os teólogos associam Kairós ao tempo de Divino, termo é assim descrito na teologia para descrever a forma qualitativa do tempo, como o "tempo de Deus” (a eternidade), enquanto Chronos é de natureza quantitativa, o «tempo dos homens».

Analogamente, Kairós provoca uma descontinuidade nesse tempo burocrático de Chronos, propiciando-nos ocasiões diversas, mas a realização de um tempo especial, significativo, fica por nossa conta: “o momento fugaz em que uma oportunidade abertura se apresenta e deve ser encarada com força e destreza para que o sucesso seja alcançado”. Afinal, somos os protagonistas de nossa própria história.

Essa passagem do tempo nos é percebida, através das mudanças das fases de desenvolvimento humano. Essa noção de desenvolvimento está atrelada a um contínuo de evolução, em que nós, caminharíamos ao longo de todo o ciclo vital.

Os seres humanos nascem "mergulhados em cultura”, e é claro que esta será uma das principais influências no desenvolvimento. Contudo, ainda existem discordâncias teóricas entre as abordagens que serão apresentadas adiante sobre o grau de influência da maturação biológica e da aprendizagem com o meio no desenvolvimento, o contexto cultural é o palco das principais transformações e evoluções do bebê humano ao idoso. Essa evolução nem sempre é linear, se dá em diversos campos da existência, tais como afetivo, cognitivo, social e motor. Este caminhar contínuo não é determinado apenas por processos de maturação biológicos ou genéticos. $\mathrm{O}$ meio "e por meio entenda-se algo muito amplo, que envolve cultura, sociedade, práticas e 
interações” é fator de máxima importância no desenvolvimento humano (RABELLO, 2016)

Dando continuidade, na proposta, junto aos alunos idosos, foi solicitado, aos mesmos, que num arranjo de subgrupos, refletissem no coletivo sobre as marcas do Tempo, na perspectiva passada de cinco anos, regendo seus pensamentos na alusão da composição da influência dos Deuses Chronos e Kairós, dentro da história mitológica da época dos gregos.

Participaram 09 alunos (02 homens e 07 mulheres), na faixa etária de 57 a 77anos. Foram formados 3 subgrupos considerando as lembranças registradas nas folhas de papel, de onde surgiram os seguintes relatos :

\section{$1^{\mathrm{o}}$ subgrupo, (C./Ja./I)}

Sentem-se muito felizes; desfrutam de certo conforto, na forma material;

$\mathrm{Na}$ perspectiva de pensarem cinco anos atrás, todas passaram por um momento de questionamento - Quem sou Eu? O que estou fazendo?

Gostam de estar na Companhia de pessoas agradáveis; de fazerem novos amigos, valorizam muito esse conviver, uma, de forma muito especial em razão de ter tido um Acidente Vascular Cerebral- AVC, que felizmente passou de forma mais branda dando-lhes condições de recuperação, e sem sequelas, assim o fato de estar em grupo, lhe faz muito bem, passou assim a valorizar todo o tempo que está vivendo, assim quer conversar, viajar enfim viver; poder dar um novo sentido na sua vida; acho que nasci de novo; foi unânime, para as três - que de forma geral os cinco anos para trás, foram momentos fáceis mas também difíceis, como também momentos de vitória; de conquistas...Vencendo, cada etapa de suas vidas, conseguindo dar encaminhamento aos filhos - uma, teve a condição de casar a filha na forma tradicional ; de véu e grinalda, sentiu-se muito grata por ter realizado esse sonho;
Outra, de forma especial quer se dedicar a escrita de livros, se descobriu escritora, Tem um desejo deixar escrito suas coisas para seus netos para que eles possam lembrar Minha Avó era pra frente!!! Frequentava a universidade! ela fazia o NETI. Outro relato diz, que os momentos tristes de perdas gerais de amigos, ou de oportunidades não vividas, leva-a, sentir-se com uma fita preta no coração simbolizando as perdas de familiares ou de pessoas queridas; Todas foram unânimes, relataram e foram afirmativas que, passaram a Valorizar muito a vida em família para continuarem tendo um sentido na vida;

$2^{\circ}$ Grupo (Jo./M./S)

A história desses três protagonistas -

A vida é maravilhosa, tudo bem, às coisas, às vezes acontecem tendo uma expectativa, porém acabam tendo outro rumo, por um algum obstáculo de percurso (doença, morte, etc.), mas temos que retomar o rumo da vida; e vive-la com essas mudanças;

Uma, leva a vida bem cronometrada, por questões fisiológicas, de saúde, para poder se manter bem, segue uma rotina de horários, para caminhar, para ginástica, para hora do curso, da academia, sem autos e baixos; atualmente percebe-se como cuidadora da mãe de 97 anos, que lhe esta ensinando e entendendo toda essa trajetória das nossas vidas, sua mãe lhe da lições de vida , um exemplo de que como temos que investir nas relações familiares e a sua importância;

Outra, a história da sua vida, dentro desse espaço de tempo, de há cinco ou seis atrás, sente que sempre foi criada para ser dona de casa, de esposa, de caminhar; de tempo de doença, do marido internado, a perda do companheiro, onde o filho após ter passado no vestibular de medicina, abraçou pai no leito do hospital dando resultados do vestibular de Medicina-diz ainda que o filho pensa e acredita que irá encontrar-se com 
um pai, um dia e falar sobre esse momento, de realização profissional, de vir desfrutar e dizer que ele foi sua grande inspiração de conquista da sua graduação; do geral sente-se grata pelo momento que esta vivendo, pois luta com a sua saúde, quer ficar longe da depressão, enfim quer se alimentar de coisas boas da vida

\section{$3^{\circ}$ Grupo (To/Je/E.)}

O grupo frente a proposta de repensar nos cinco anos passados, viram somente coisas boas, alimentando-se dessa visão otimista de mundo, tendo a impressão que precisam ter ou cultivar essa visão, pois sentem a sensação de um passado muito recente ainda, parecendo que estão vivendo num presente, continuo, mudanças na vida como aposentados; mudanças de cidade; de estar indo morar com o filho que veio estudar na universidade (UFSC); mudança com aquisição de um carro novo; mudança no casamento, possibilidade de construção de novos vínculos afetivos, viagens realizadas, vida religiosa, que lhe responde para dar suporte nas coisas que lhes acontecem, passaram a valorizar o tempo de vida que estão vivendo. Acreditando que o futuro ainda lhes reservam as melhores coisas, isso lhes fortalecem para ter condição de viver uma vida com qualidade, a participação em grupo é um fator diferencial para essas conquistas, assim eles se sentem.

\section{Considerações finais}

A partir da convivência expressa na relação dos alunos idosos com os espaços institucionais, na medida em que se inserem numa proposta pedagógica, igualmente levada pela grade curricular do CFMAG, os mesmos acabam identificando-se com esses espaços acadêmicos, as denominadas Instituições de Ensino Superior - IES, passando a configurar-se como um espaço intergeracional de troca de saberes. "Os idosos buscam respostas diferentes para seu envelhecimento." (CACHIONI 2003).

Contudo, aprender em tempo de viver, são lições de vida abrangentes à todas gerações que marcam o ciclo de vida de todos os seres humanos.

Pela interação social, aprendemos e nos desenvolvemos, criamos novas formas de agir no mundo, ampliando nossas ferramentas de atuação neste contexto cultural complexo que encerra as nossas vidas, e se desencadeia durante toda nossa existência nesse plano de vida corporal.

Para Camargo (2000), o tempo no inconsciente não é cronológico. Os horários impostos pela sociedade são assimilados conscientemente, como regra estabelecida socialmente ou que se deva ser seguida por todos, para que possamos ter uma convivência. Somos controlados por uma agenda profissional, social, ditando a hora certa em que algo tenha que ser feito. Partindo desse olhar sobre o tempo como algo poderoso, que venha governar as nossas vidas, muitas pessoas tendem a negar que não conseguem administrar bem o seu tempo, pois também reconhecem que lidar com esse tempo não é uma tarefa fácil.

Esse sentimento de impotência de controle do tempo pode levar as pessoas a certa insatisfação com a própria vida, por não ter aproveitado mais...

Assim as nossas experiências são vividas e valorizadas dentro de cada contexto social, para um bom viver e envelhecer, e que quando acrescentamos qualidade na nossa vida, transcendemos o tempo cronológico (perdemos até a noção de tempo muitas vezes) e por esse tempo qualitativo descontinuamos o que é continuo.

Nesse relato todos se sentiram com um talento para historiar os seus destinos, sentem-se fortalecidos por estarem em grupo, essa 
dinâmica de trabalho de grupo, leva-os a perceberem que poderiam estar vivendo outras situações, mais amargas e ou infelizes, mas sentem-se, na condição de estarem desfrutando, desse espaço, proposto pelo CFMAG, junto à universidade, que essa condição de alunos idosos, favorecem em muito o curso de suas vidas, é um educar-se contínuo para o enfrentamento da velhice.

A perspectiva de viver um envelhecimento ativo os coloca numa plataforma de independência, podendo ter uma expressão maior de espaços; de participação de sentirem-se ativos e vivos, de assistência e proteção de direitos fundamentais e sociais, e de autorrealização podendo aproveitar todo o tempo proporcionado nas trocas das relações sociais e institucionais e de dignidade levando-os a um viver digno e com segurança, sem ser explorado e ou vir a sofrer violências, físicas, psicológicas, financeiras, sexuais, abuso e ou negligências de outros.

Enfim, de poderem se sentir sadios e felizes, de reconhecerem que cada um tem um significado para o outro, que as experiências compartilhadas expressam uma nova dimensão de tempo, do nosso tempo, do tempo individual de cada um, do tempo desfrutado e direcionado, a vencer desafios e conquistas e a perspectiva de poder viver um novo tempo compartilhado, desfrutado junto a um contexto sociocultural, com experiências múltiplas.

Concluiu-se na finalização dessa proposta que o convívio grupal e o compartilhar os saberes junto ao CFMAG leva os idosos a sentirem-se felizes em desfrutar do momento presente, despertando para alguns uma inclinação poética e uma unanimidade na valorização da vida familiar; que com relação aos seus planos de vida, às vezes, seguem outros rumos, às vezes, somos muito metódicos, disciplinados, na intenção de manter um equilibro mental e corporal, às vezes uma vida doméstica se reflete na responsabilidade de cuidar do outro e nos percebemos cuidadores natos; e a necessidade de investir sempre nas relações familiares; demonstraram uma visão otimista pela vida vivida, vendo só coisas boas, que as mudanças precisam acontecer para que a vida nova possa ser significativa, como mudança de cidade, de estado, da compra de um carro novo, mudança na vida conjugal, enfim, são aspectos naturais de percurso de quem está vivo na vida e assim passa a valorizar esse tempo que está vivendo.

Kairós está sim associado a grandes oportunidades ou momentos marcantes, ou ainda tomadas de decisões importantes, mas não se limita a isso. Kairós é o nosso próprio tempo vivido em paralelo às horas, aos dias e aos meses do ano.

Ressaltando Camargo (2000) "nossas percepções do tempo são relativas, depende muito da nossa história de vida”. De certa forma, direta ou indiretamente, as experiências individuais externas e internas, bem como o nosso contexto cultural vão interferir na concepção do tempo de cada um.

\section{Referências}

CACHIONI, M. Quem educa os idosos?: um estudo sobre professores de universidade da terceira idade. Campinas: Editora Alínea, 2003

CAMARGO, M.S. 24 horas por dia.: quanto tempo tem? Rio de Janeiro: Rocco, 2000.

DADOS SOBRE O ENVELHECIMENTO NO BRASIL: Disponíveis em: www.sdh. gov.br/assunto (http://selosdadonajamylle. blogspot.com/2009/10/s elo-23. htmhttp://www.sdh.gov.br/assuntos/ pessoa-idosa/dados-estatisticos/ DadossobreoenvelhecimentonoBrasil.pdf 17/07/2016 -7.17min. 
DEBERT, G. G. O discurso gerontológico e as novas imagens do envelhecimento. São Paulo em Perspectiva, v.7, n. 4, p.121-8, out/ dez.1993.

DELORS J. (Org.) Educação: um tesouro a descobrir. São Paulo: Cortez; Brasília: MEC: UNESCO, 2000.

FREIRE P. Pedagogia da autonomia: saberes necessários à prática educativa. Ed. Paz e Terra, SP. 1999.

KALACHE, A.; VERAS, R. P.; RAMOS, L. R. O envelhecimento da população mundial: um desafio novo. Revista de Saúde Pública, v.21, p.200-206, 1987

RABELLO, E. T.; PASSOS, J. S. Vygotsky e o desenvolvimento humano. Disponível em < http://www.josesilveira.com> no dia 20 de julho de 2016

REVISTA PANDORA BRASIL - No 69 “Chrónos e Kairos” - Dezembro de 2015 ISSN 2175-3318

RICHARD, C. Chronos e Kairós. Londres: Kegan Paul, Trench, Trübner, \&Co. Ltd. 1894. p.209-212.

SABÓIA, I. B. de. Chronos e Kairós: reflexões sobre temporalidade laboral e solvência social. In www.repositório.ufc. br; acesso em 14/11/2015. Dissertação (Mestrado em Psicologia) - Universidade Federal do Ceará, Fortaleza, 2007. TRENCH, 